\title{
Effect of Rain Distribution Alteration on Splash Dispersal of Colletotrichum acutatum
}

\author{
N. Ntahimpera, L. V. Madden, and L. L. Wilson
}

Department of Plant Pathology, The Ohio State University, Ohio Agricultural Research and Development Center (OARDC), Wooster 44691. Accepted for publication 17 March 1997.

\begin{abstract}
Ntahimpera, N., Madden, L. V., and Wilson, L. L. 1997. Effect of rain distribution alteration on splash dispersal of Colletotrichum acutatum. Phytopathology 87:649-655.

Splash dispersal of Colletotrichum acutatum conidia from infected strawberry fruit was assessed using a rain simulator to determine the properties of rain (e.g., intensity [millimeters/hour] or drop size distribution) most related to dissemination. Dispersal with a simulated rain corresponding to a natural rain of about $11 \mathrm{~mm} / \mathrm{h}$ was compared with dispersal of three other simulated rains that had larger and smaller drop sizes, on average, than idealized natural rains. Splash droplets were collected in sheltered petri plates with a selective medium for Colletotrichum, and colonies formed from conidia entrained in the droplets were counted and used as the measure of dispersal. Colonies were mostly confined to a $27-$ $\mathrm{cm}$ radius from the source, and density of colonies decreased exponen-
\end{abstract}

ABSTRACT tially with the distance squared, as indicated by the fit of a diffusion-type model to the data. Splash dispersal was more affected by drop size distribution than rain intensity or other properties of the generated rains. That is, there was a direct positive relationship between total colonies over 61 min of rain for a circular area with a $72-\mathrm{cm}$ radius $(\Sigma)$ and the mass (volume) median diameter of impacting drops $\left(D_{0}{ }^{\prime}\right)$ for four rain-simulation treatments. In a separate study, strawberry fruit were exposed to the same four simulated rains at two distances from a point source and for two rain durations. Although the proportion of infected fruit $(y)$ increased with time and decreased with distance, rain treatment did not significantly affect $y$, as predicted based on past work with a wide range of intensities of simulated rains.

Additional keywords: anthracnose, disease spread, Fragaria $\times$ ananassa, models, quantitative epidemiology.
The propagules of many fungal plant pathogens are dispersed from infected hosts by rain splash $(10,12,14,15)$. Dispersal occurs by the impact of water drops onto an inoculum-bearing surface, the entrainment of spores in splash droplets, and the movement of droplets to new locations $(10,12,14,38)$. Splash dispersal is positively affected by the size and velocity of individual incident raindrops $(8,10,36)$.

Rain is an environmental variable with many attributes (23). It has spatial and temporal characteristics (time of event, frequency, and rain duration) and intensity features. Rain intensity is an indication not only of the volume of water incident on a unit of area per unit of time, but also the number and size distribution of drops, as well as kinetic energy of the drop impactions $(23,30)$. Intensity of rain can have a positive, negative, or no significant effect on new plant infections resulting from dispersal $(2,19,22,25)$, even though increasing intensity simultaneously increases incident rain volume, number of drops, and drop sizes.

Strawberry anthracnose is caused by several Colletotrichum species (28), with the dominant species in many parts of the United States being $C$. acutatum J.H. Simmonds. Conidia of $C$. acutatum are produced in acervuli, a characteristic of rain-splashed fungi $(8,14)$. Previous studies of $C$. acutatum have characterized the physical aspects of dispersal from single-drop impactions and from simulated rain over an experimental area, and quantified the effects of surface topography and plant density on dispersal and disease spread $(2,16,34,38)$. Recently, Madden et al. (19) characterized the relationship between rain intensity and splash dispersal of $C$. acutatum for a wide range of intensities. Number of dispersed spores increased with increasing intensity, as expected

Corresponding author: L. V. Madden

E-mail address: 1madden@ @ostbox.acs.ohio-state.edu

Publication no. P-1997-0407-03R

(C) 1997 The American Phytopathological Society based on properties of rain and known effects of single-drop impactions on dispersal $(36,37)$, but there was also a nonlinear relationship between rain intensity and proportion of fruit exposed to the rain that became infected by $C$. acutatum (39). Maximum fruit infection occurred at an intermediate rain intensity corresponding to about $30 \mathrm{~mm} / \mathrm{h}$ (19). Although more spores were removed from the source as intensity increased, wash-off of spores from potential infection sites also increased, thus, giving the nonlinear response.

In the study by Madden et al. (19), increasing rain intensity was accomplished by increasing number and size of simulated raindrops, incident volume of water per unit of area and time, and, presumably, kinetic energy. This was intended to duplicate intensity characteristics of natural rains of a single idealized type (e.g., shower, thunderstorm) (30). Thus, it was not possible to determine which component of rain was the determinant for the measured dispersal effects.

The objective of this study was to determine how splash dispersal of $C$. acutatum is affected by generated rains with drop distributions different from idealized natural rains. Specifically, rains were generated that had larger and smaller drop sizes, on average, than natural rains of a single type. It was hypothesized that splash dispersal for rains of similar incident water volume per unit of area and time (i.e., intensity) would be greatest for the rains with larger drop sizes. It was further hypothesized that fruit infection would not be related to the altered rain distribution, because of the complicated relation previously found between rain intensity and fruit disease incidence. Preliminary results were previously reported (21).

\section{MATERIALS AND METHODS}

Rain generation system. A rain simulator that was developed at The Ohio State University, Ohio Agricultural Research and Development Center (26), was used to investigate the effect of altering rain intensity on the dispersal of conidia. The system con- 
sisted of an upward-pointing and rotating wide-angle spray nozzle (Spraying Systems Inc., Wheaton, IL) that produced a conical pattern and ensured generation of a uniform rain at the ground surface over an $1.2 \times 1.2-\mathrm{m}$ experimental area. The height of drop fall was $4 \mathrm{~m}$ with water pressure levels of 69 or $138 \mathrm{kPa}$ at the nozzle orifice, which were maintained constantly with a precision flow valve. Two spray nozzles, $10 \mathrm{~W}$ and $20 \mathrm{~W}$ (19), were used individually in this study to generate simulated rains.

Effects of rain intensity alteration on splash dispersal of $C$. acutatum was studied using the rain simulations produced by the following four nozzle/pressure combinations. The standard treatment, used as a basis for comparison with others, was the $20 \mathrm{~W}$ nozzle with $69 \mathrm{kPa}$ of water pressure (Table 1). The cumulative volume distribution was similar to the long-term average for a natural rain of $11 \mathrm{~mm} / \mathrm{h}(14,23)$. The second treatment was the $20 \mathrm{~W}$ nozzle with $138 \mathrm{kPa}$ of water pressure, which produced higher rain intensity (i.e., higher milliliters per square centimeter per minute, or millimeters per hour), but with smaller drops, on average, than for the standard treatment. The third treatment had the same nozzle and pressure as the standard treatment, but with a horizontal screen $(1 \times 1 \mathrm{~m})$ placed directly below the nozzle. The screen was $30 \%$ actual shade of woven synthetic fabrics (Lumite Inc., Gainesville, GA). Water collected on and then dripped through the screen in an attempt to produce about the same intensity as with no screen, but with larger drop sizes. The last treatment used a smaller nozzle (10W) than the standard treatment and with the higher water pressure $(138 \mathrm{kPa})$. This treatment was used in an attempt to produce a similar volume as the standard treatment, but with more and smaller drops, on average. For both the $10 \mathrm{~W}$ and $20 \mathrm{~W}$ nozzles, idealized natural rains only are obtained using a pressure of $69 \mathrm{kPa}(19)$.

The intensity was determined for each treatment as described by Reynolds et al. (24). Twelve 10 -cm-diameter funnels were placed in cylinders, approximately evenly distributed over the experimental area. Rain was generated for $15 \mathrm{~min}$, and the volume of water collected was determined and converted to milliliters per square centimeter per hour. Intensity was evaluated three times for each treatment. For the nozzle/pressure treatments $10 \mathrm{~W} / 138 \mathrm{kPa}$, $20 \mathrm{~W} / 69 \mathrm{kPa}$, and $20 \mathrm{~W} / 138 \mathrm{kPa}$, cumulative volume distribution (proportion of total water volume accounted for by drops less than or equal to a certain diameter) was determined from drop size data provided by the manufacturer (Spraying Systems Inc.). For the treatment consisting of $20 \mathrm{~W} / 69 \mathrm{kPa}$ with the screen, drops were collected on water sensitive paper (WSP) (Spraying Systems Inc.), as was previously done for single-drop studies $(24,26)$. Thirtyseven $75 \times 52-\mathrm{mm}$ cards of WSP were exposed immediately above the target area for about $1 \mathrm{~s}$, and then dried. The diameters of drop traces on WSP were determined with an image analyzing computer (Dapple Systems Inc., Sunnyvale, CA) following the method described in Reynolds et al. (26). The equivalent diameter of circles was calculated based on a spread factor of two (26).

The mass (volume) median diameter $\left(D_{0}{ }^{\prime}\right)$ of impacting incident drops (per unit of area and time) was determined from the cumulative volume distribution. Half of the volume or mass of incident rain is determined by drops less than (or greater than) this diameter (19). $D_{0}^{\prime}$ is directly related to, but slightly larger than, the mass median diameter of drops per cubic meter of air above a surface $\left(D_{0}\right)$. For natural rains of a single type, $D_{0}$ (and, hence, $\left.D_{0}{ }^{\prime}\right)$ increases with intensity (30).

Inoculum. The isolate of $C$. acutatum used in this experiment (ATCC 90170) was the same as in the previous studies $(33,38,39)$. To maintain pathogenicity, strawberry fruit were inoculated with the fungus regularly, and the fungus was then reisolated from infected fruit by scraping conidia from infected fruit and streaking on potato dextrose agar (PDA) $(33,39)$. Cultures were incubated in the dark at $25^{\circ} \mathrm{C}$ for up to 7 days. Spore suspensions were prepared by scraping conidia from cultures and suspending them in deionized water. The density was adjusted to $10^{5}$ conidia per milliliter with the aid of a hemacytometer.

To prepare inoculum-source fruit for dispersal tests, detached, immature (green-to-white stage) strawberry fruit from greenhouse-grown plants were washed with deionized water, surfacesterilized in $70 \%$ ethanol for $60 \mathrm{~s}$, rinsed with deionized water, dried, and placed on elevated screens (6-mm mesh) contained in 5-liter plastic containers. The containers were filled with $\sim 700 \mathrm{ml}$ of deionized water. The pedicel of each fruit was inserted through the mesh of the metal screen and immersed in water to minimize fruit desiccation. Fruit were then sprayed to runoff with the conidial suspension. The containers were closed and incubated at $25^{\circ} \mathrm{C}$ for $24 \mathrm{~h}$ to ensure infection (33), after which time, the lids were removed, and the fruit were kept at $25^{\circ} \mathrm{C}$ for 7 days to ensure lesion development and sporulation.

Sheltered gravity samplers and spore deposition. Gravity samplers, consisting of petri plates with selective media shielded from rain, were used to sample conidia of $C$. acutatum dispersed in rain splash droplets. A wood frame $(1.5 \times 1.5 \mathrm{~m})$ was placed immediately below the rain generator $(38,39)$. The frame was covered with a steam-sterilized soil mix to a depth of about $3 \mathrm{~cm}$.

TABLE 1. Characteristics of rain-simulator spray nozzles, rain intensity, splashed intensity, and colonies of Colletotrichum acutatum in petri plates for four treatments

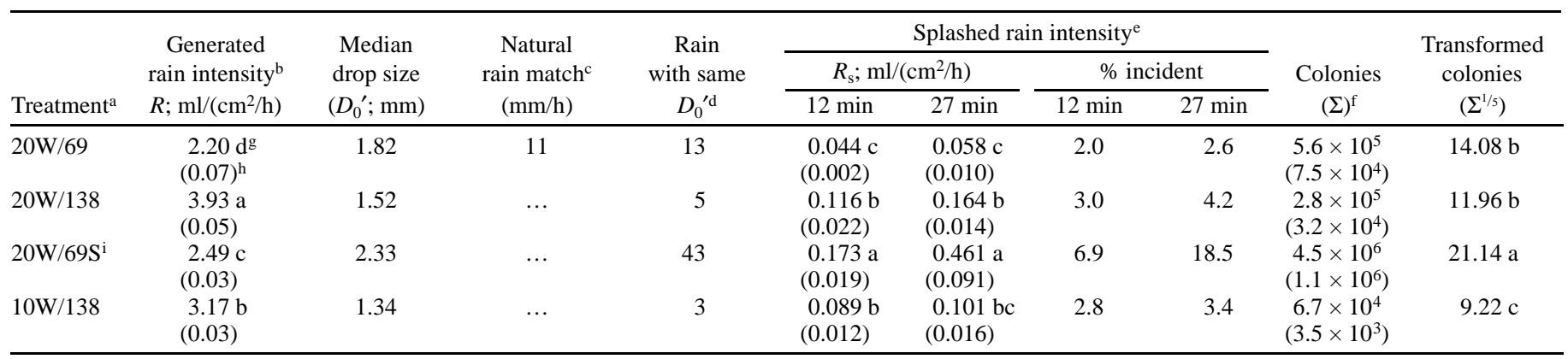

a Nozzle/pressure $(\mathrm{kPa})$.

${ }^{\mathrm{b}}$ Direct interception of generated rain in funnels.



${ }^{\mathrm{d}}$ Determined by using equations in the appendix of Madden et al. (19).

e Intensity of splashed water into sheltered petri plates at two times during a generated rain episode. Percentage determined by dividing $100 R_{s}$ by $R$.

${ }^{\mathrm{f}}$ Colonies obtained by integration over a circular area of a $72-\mathrm{cm}$ radius for $61 \mathrm{~min}$.

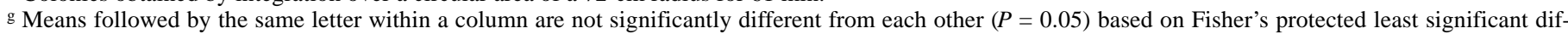
ference.

${ }^{\mathrm{h}}$ Standard error in parentheses. Number of replications is three.

i $\mathrm{S}=$ Horizontal screen placed immediately below the spray nozzle. 
The mix was made of soil and peat moss (5:1, by volume), supplemented with $150 \mathrm{~g}$ of 9-45-15 N-P-K fertilizer and lime. This soil was discarded after each test run. To determine the volume of splashed water, five sheltered gravity samplers (38) were placed approximately randomly over the experimental area, with the constraint that there was at least $40 \mathrm{~cm}$ between samplers. Petri plates (9-cm diameter) with selective medium for Colletotrichum (5) were labeled and weighed immediately before use. At 12 and 27 min into a simulated rain, plates were placed under the rain shields for 2 to $3 \mathrm{~min}$ of exposure. The shields prevented collection of directly impacting raindrops. Plates were collected and immediately weighed again to determine the weight gain due to water splashed into each plate. Controls consisted of three plates with media that were weighed at the same time, but not exposed to rain. Average weight loss in the control plates, due to evaporation of water in the media, was used to correct the weight changes in the rain-exposed plates. Means of splashed water intensity were determined for each test run of the rain simulation after converting to volumetric units of milliliters per square centimeter per hour, based on the unit density of water. Splash for each rain intensity was tested three times.

For splash-dispersal determination, the frame was covered evenly with sterilized soil mix, and five inoculated fruit with sporulating lesions were clustered on the ground 30 to $40 \mathrm{~cm}$ from one corner of the frame (Fig. 1 in literature citation 38). Petri plates $(6-\mathrm{cm}$ diameter) containing the selective medium for $\mathrm{Col}$ etotrichum (5) were positioned, with the lids removed, under metal rain shields at $12,27,42,57$, and $72 \mathrm{~cm}$ (one plate for each distance) from the inoculum source, as described by Madden (14) and Yang et al. (38). To test for contamination of the soil cover, one plate was placed under rain shelters and exposed to $1 \mathrm{~min}$ of rain before introducing the source fruit. Starting at 0 min into a simulated rain, plates were exposed to splashing water every 5 min for 1-min periods, for a total duration of $61 \mathrm{~min}$. New plates were used for each time period and distance. Exposed plates were covered with lids and incubated at $25^{\circ} \mathrm{C}$ for 2 days. The plates were then transferred to a refrigerator at $6^{\circ} \mathrm{C}$ for 2 to 3 days. For each plate, Colletotrichum colonies corresponding to each time (rain duration) and distance from the source were counted with the aid of a magnifying plate counter (New Brunswick Scientific Co., Inc., New Brunswick, NJ). Simulation runs were done at least three times for each treatment. Periodically, representative colonies were transferred to PDA medium to obtain greater sporulation for examination of morphological characteristics and positive fungal identification.

Fruit disease incidence study. Strawberry plants (cv. Midway) were raised from transplants in 15 -cm-diameter pots containing sterilized soil mix (soil/peat/sand, 2:2:1, by volume) in a greenhouse. Twenty plants were used for each rain simulation. Methods were the same as those used previously by Madden et al. $(18,19)$. Potted plants were supported by a wood frame $(1.5 \times 1.5 \mathrm{~m})$ in two concentric circles (30- and $60-\mathrm{cm}$ radii) placed directly below the rain generator (18). The frame was covered by sterilized soil mix so that the soil level was even with the base of the plants. Five infected source fruit (prepared as for the gravity sampler study) were placed in a tight cluster on the soil in the center of the circles. To maintain the consistency of number and location of the sample fruit for each treatment, 40 detached, healthy, immature strawberry fruit were placed on the soil surface immediately in front of the inner part of the plant crown in each of the two circles. The entire area was rained on for $16 \mathrm{~min}$ (18). At 4 and $16 \mathrm{~min}$ into the rain episode, 20 exposed fruit from each circle were collected and placed on elevated wire-mesh screens in 5-liter containers, covered, and incubated at $25^{\circ} \mathrm{C}$. After $24 \mathrm{~h}$, the lids were removed to allow natural drying. Pedicel ends were cut afterwards, and the fruit were placed back into the containers with their pedicels inserted through the wire-mesh screens into deionized water. Containers were returned into the incubator $\left(25^{\circ} \mathrm{C}\right)$, and assessment of fruit infection was made by visual examination of each fruit at 7 days after each rain simulation. The proportion of infected fruit (disease incidence) was used as the measure of conidia dispersal $(14,18)$.

Data analysis. Number of colonies in a petri plate, converted to unit of area and time ( $Y$ [number per square centimeter per minute]) was determined for each distance, time (rain duration), treatment, and repetition. $Y$ is proportional to the deposition flux density of conidia (35). Assuming equal dispersal in all directions because of lack of air flow, the interpolated total number of colonies $(\Sigma)$ during each 61-min period over a circular area with a radius of $72 \mathrm{~cm}$ (the maximum distance measured) was estimated by numerical integration over both the distance and time domains. The integration was done following Simpson's $3 / 8$ rule with the aid of the SURFER software (Golden Software, Inc., Golden, CO).

Analysis of variance (ANOVA) was performed on incident rain, volume of water splashed, total number of colonies $(\Sigma)$, and fruit disease incidence. For each treatment, means and their standard errors were calculated prior to transformation. To stabilize the variances, $\Sigma$ was transformed to $\Sigma^{1 / 5}$ before statistical analysis $(15,19)$. Square-root transformation was performed on splashed rain intensity. Likewise, the proportion of infected fruit $(y)$ was transformed using the complementary log-log transformation, $y^{*}=$ $\ln [-\ln (1-y)]$. For fruit disease incidence, ANOVA was performed on $y^{*}$ as a repeated measures experiment (19), in which treatments and block (experiment repetition) were the randomized factors; distance from the source and rain duration were, respectively, spatially and temporally repeated measures.

The diffusion-type model (35) was fitted to the colony data to describe mean $Y$ as a function of rain duration ( $t$; minutes) and distance from the source ( $s$; centimeters). Parameters of the model were $Q^{\prime}$ (per minute), representing the initial release of spores from the inoculum source, related to inoculum density on the fruit and properties of the simulated rain $(14,35) ; \alpha$ (square centimeters per minute), inversely related to the steepness of the spore deposition gradient and a measure of the average flight distance of splash droplets; and $\gamma$ (per minute), representing the rate of spore loss from the system (e.g., infiltration of spores through the soil). Parameters were estimated by nonlinear least squares using the NLIN procedure of SAS (SAS Institute, Inc., Cary, NC).

\section{RESULTS}

Characteristics of generated rains. Incident rain volumes (per unit of area and time) of the different treatments were significantly different from each other $(P<0.001)$, based on ANOVA (Table 1). Variability was very low. The standard treatment $(20 \mathrm{~W} / 69 \mathrm{kPa})$ produced the lowest volume of water. Placing a horizontal screen below the nozzle orifice resulted in a slightly higher incident rain volume than the standard treatment (Table 1), presumably because the water first accumulated before dripping onto the experimental area. Using the same nozzle at higher pressure $(20 \mathrm{~W} / 138 \mathrm{kPa})$ produced $79 \%$ higher incident rain than the standard treatment. Incident rain volume generated by the small nozzle at higher water pressure $(10 \mathrm{~W} / 138 \mathrm{kPa})$ was $44 \%$ higher than the standard treatment (Table 1).

The cumulative volume distributions of simulated rains are represented in Figure 1. The curves of the small nozzle at higher pressure $(10 \mathrm{~W} / 138 \mathrm{kPa})$ and that of $20 \mathrm{~W} / 138 \mathrm{kPa}$ were located to the left of the cumulative distribution of the standard treatment, indicating the smaller drop sizes overall. The cumulative volume distribution for the screen treatment was located to the right of the standard treatment for drop diameters less than $2.7 \mathrm{~mm}$. For larger drop sizes, the distribution for the screen treatment abruptly reached its maximum $(100 \%)$. Mass median drop diameter $\left(D_{0}^{\prime}\right)$, shown by the horizontal line in Figure 1, was reduced by increasing water pressure at the $20 \mathrm{~W}$ nozzle orifice (Table 1), as expected. For the $10 \mathrm{~W}$ nozzle at $138 \mathrm{kPa}, D_{0}{ }^{\prime}$ also was less than for 
the standard treatment. The $20 \mathrm{~W} / 69 \mathrm{kPa}$ with the screen resulted in a $D_{0}{ }^{\prime}$ of $2.3 \mathrm{~mm}, 28 \%$ higher than for the standard treatment.

The standard treatment $(20 \mathrm{~W} / 69 \mathrm{kPa})$ produced a rain that had a cumulative volume distribution matching the one of an idealized natural rain of $\sim 11 \mathrm{~mm} / \mathrm{h}$ (Table 1) (19). Other treatments were

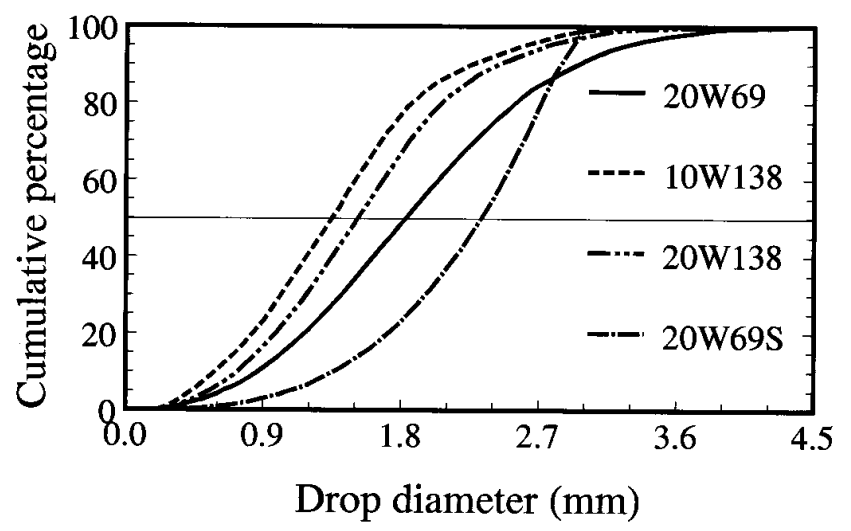

Fig. 1. Cumulative drop volume distributions of rain generated by four treatments using a rain simulator (24). Line labels indicate the nozzle (10W or $20 \mathrm{~W}$ ) and water pressure at the nozzle orifice (69 or $138 \mathrm{kPa})$. The 20W69S label corresponds to the treatment in which a horizontal screen was placed immediately below the nozzle. selected so that the rains did not match idealized rains of a single type (e.g., thunderstorms) based on the Marshall-Palmer theory (20). However, natural rains that had the same $D_{0}{ }^{\prime}$ as the generated rains were determined using Ulbrich (30) and the equations in the appendix of Madden et al. (19). Specifically, because $D_{0}=$ $3.67 /\left(41 I^{-0.21}\right)(19)$, with $I$ being rain intensity represented as millimeters per hour, it can be shown that $D_{0}{ }^{\prime}=4.34 /\left(41 I^{-0.21}\right)$ (L. V. Madden, unpublished data). Natural rains with the same $D_{0}^{\prime}$ as found for $10 \mathrm{~W} / 138 \mathrm{kPa}$ and $20 \mathrm{~W} / 138 \mathrm{kPa}$ had intensities of 3 and $5 \mathrm{~mm} / \mathrm{h}$, respectively, even though the generated volume of water for these treatments was greater than for the standard $(11 \mathrm{~mm} / \mathrm{h})$ treatment. A natural rain with a $D_{0}{ }^{\prime}$ of $2.3 \mathrm{~mm}$ (as found for the screen treatment) would have an intensity greater than $40 \mathrm{~mm} / \mathrm{h}$ (Table 1).

For all treatments, the volume of water splashed was lower after 12 min than after 27 min of rain application (Table 1), and treatment had a significant effect on volume splashed $(P=0.002)$. After 12 min, splashed water with the standard treatment $(20 \mathrm{~W} / 69$ $\mathrm{kPa})$ was slightly, but significantly $(P=0.05)$, less than splashed water with other treatments (Table 1). The treatments $10 \mathrm{~W} / 138$ $\mathrm{kPa}$ and $20 \mathrm{~W} / 138 \mathrm{kPa}$ had similar splash water intensities; however, the treatment with the screen had a much higher splash intensity than the others. The percentage of water splashed relative to incident rain was 2 to $7 \%$, with the largest percentage for the screen treatment. Similar results were obtained after $27 \mathrm{~min}$ of rain application (Table 1), except that overall amounts and percentages were higher as the soil approached saturation.
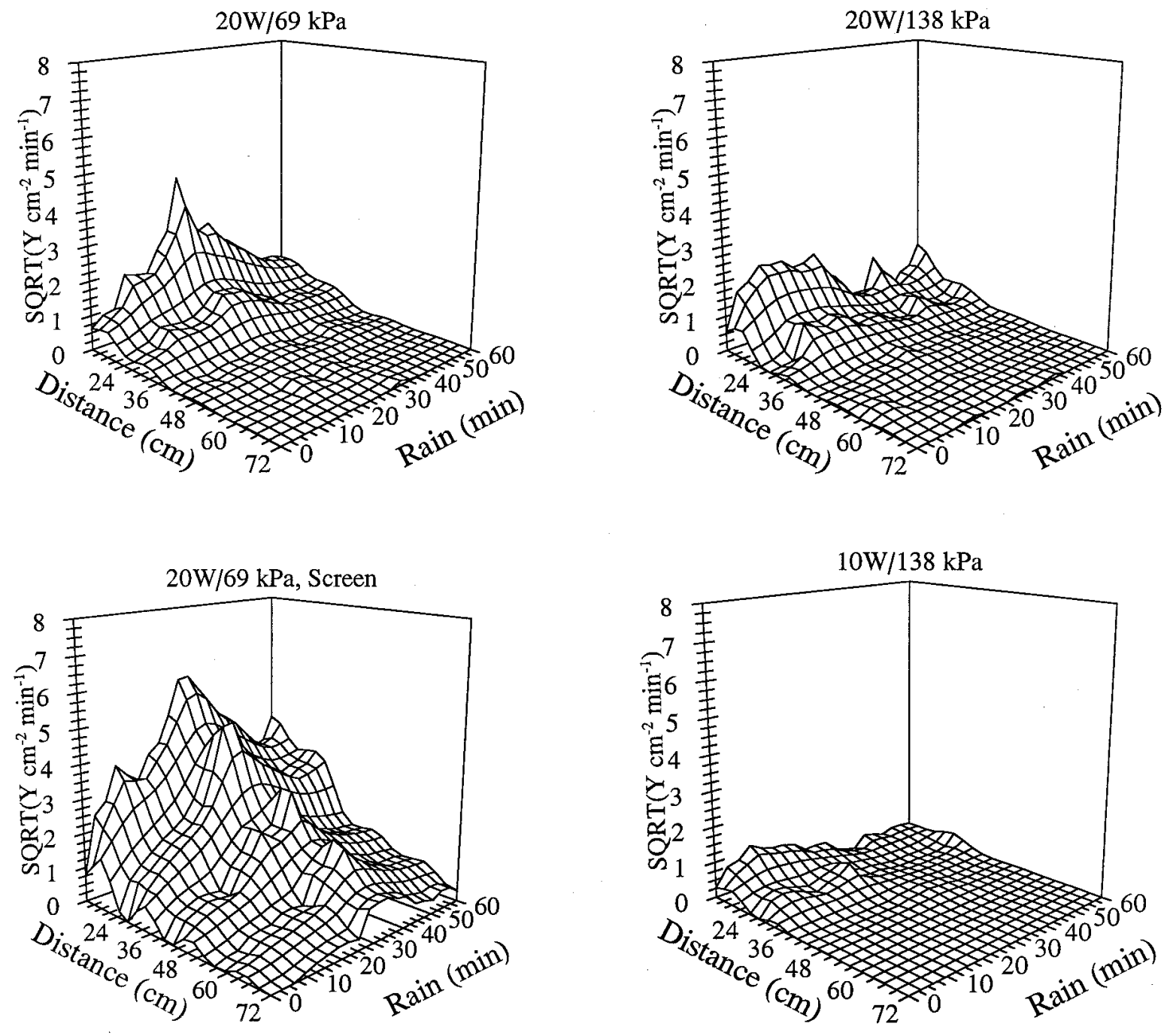

Fig. 2. Mean number of Colletotrichum acutatum colonies $\left(Y ; \mathrm{cm}^{-2} \mathrm{~min}^{-1}\right)$ on a selective medium (under a rain shield) in relation to rain duration $(t ;$ min) and distance $(s ; \mathrm{cm})$ from the inoculum source for four rain simulation treatments. Numbers above the figures refer to nozzle (10W or $20 \mathrm{~W})$ and pressure $(69$ or 138 $\mathrm{kPa})$. Square-root of $Y(\mathrm{SQRT}[Y])$ was used to better illustrate the data at $42 \mathrm{~cm}$ and beyond, where colony density was low. 
Gravity sampler study. The pattern of mean colony density $(Y)$ for each treatment with respect to rain duration and distance from inoculum source is illustrated in Figure 2. As with previous studies $(2,19,38), Y$ generally declined with distance at any time, and increased over time to a maximum and then declined. $Y$ in the $20 \mathrm{~W} / 69 \mathrm{kPa}-$ screen treatment was clearly higher than the other treatments, and $Y$ was lower in the treatments with $138 \mathrm{kPa}$ of water pressure than in the treatments with $69 \mathrm{kPa}$.

Based on ANOVA of the fifth root transformation of $\Sigma$, total colonies were significantly $(P<0.001)$ affected by the treatments (Table 1). Block (repetition) did not significantly affect results $(P$ $>0.20)$. The treatment with the screen had the highest total number of colonies, while the treatment with the small nozzle and high pressure $(10 \mathrm{~W} / 138 \mathrm{kPa})$ had the fewest total colonies. There were about eight times more colonies with the screen compared with the standard treatment (Table 1). The standard treatment had nine times as many colonies as $10 \mathrm{~W} / 138 \mathrm{kPa}$. Total colonies were strongly correlated with $D_{0}{ }^{\prime}$. A linear relationship between $\Sigma^{1 / 5}$ and $D_{0}{ }^{\prime}$ was determined by least-squares regression as:

$$
\Sigma^{1 / 5}=-6.05(1.64)+11.55(0.92) D_{0}^{\prime}
$$

in which the numbers in parentheses are the standard errors of the estimated intercept and slope. The equation had a coefficient of determination $\left(r^{2}\right)$ of $0.94(P<0.001)$.

The diffusion-type model of Yang et al. (35) gave an acceptable fit of $Y$ in relation to rain duration and distance (Table 2), except for one treatment. This indicates that $\ln (Y)$ was linearly related to distance squared (35). Values of $r^{2}$ were above 0.80 for all treatments except $20 \mathrm{~W} / 69 \mathrm{kPa}$ with the screen. The estimated parameter for initial release of spores from the inoculum source $\left(Q^{\prime}\right)$ was highest for the screen treatment $\left(74,918 \mathrm{~min}^{-1}\right)$, more than double the $Q^{\prime}$ value of the standard treatment (Table 2). The $10 \mathrm{~W} / 138 \mathrm{kPa}$ treatment had the lowest $Q^{\prime}$ estimate $\left(3,391 \mathrm{~min}^{-1}\right)$, less than a tenth of the standard treatment. There was a strong positive relationship between $Q^{\prime}$ and $\Sigma$. Rate of spore loss $(\gamma)$ was not clearly related to treatment, although there was an approximately inverse relationship between $Q^{\prime}$ and $\gamma$. Also, the standard error of the estimated $\gamma$ was large for the screen treatment, indicating that the estimate was not precise for this treatment. The parameter for the trajectory length $(\alpha)$ was estimated imprecisely as indicated by large standard errors relative to $\alpha$ (Table 2 ).

Fruit infection study. The main effects of rain duration (time) and distance from inoculum source significantly $(P=0.004)$ affected (transformed) proportion of infected fruit $\left(y^{*}\right)$ (Table 3 ). There was no significant interaction of time and distance $(P>$ $0.05)$, and block (repetition) did not significantly affect results $(P$ $>0.05$ ). Mean $y$ (across all treatments and distances) increased from 0.13 (standard error $=0.022$ ) at $4 \mathrm{~min}$ to 0.30 (standard error $=0.055$ ) at $16 \mathrm{~min}$. Mean incidence (across all treatments and times) decreased from 0.33 (standard error $=0.051$ ) at $30 \mathrm{~cm}$ to 0.10 (standard error $=0.017$ ) at $60 \mathrm{~cm}$. Inspection of individual

TABLE 2. Estimated parameters and standard errors (in parentheses) of the diffusion-type model ${ }^{\mathrm{a}}$ of Yang et al. (35) fitted to mean number of colonies of Colletotrichum acutatum $\left(Y ; \mathrm{cm}^{-2} \mathrm{~min}^{-1}\right)$ in relation to rain duration $(t ; \mathrm{min})$ and distance from inoculum source $(s ; \mathrm{cm})$ for four treatments, together with the coefficient of determination $\left(r^{2}\right)$

\begin{tabular}{lcccc}
\hline & \multicolumn{3}{c}{ Estimated parameters (standard errors) } & \\
\cline { 2 - 4 } Treatment $^{\mathrm{b}}$ & $Q^{\prime}$ & $\alpha$ & $\gamma$ & $r^{2}$ \\
\hline $20 \mathrm{~W} / 69$ & $3.6 \times 10^{4}\left(1.0 \times 10^{4}\right)$ & $0.68(1.05)$ & $0.049(0.016)$ & 0.84 \\
20W/138 & $1.0 \times 10^{4}\left(3.2 \times 10^{3}\right)$ & $2.42(2.59)$ & $0.040(0.003)$ & 0.86 \\
20W/69S & $7.5 \times 10^{4}\left(1.1 \times 10^{5}\right)$ & $0.59(2.42)$ & $0.027(0.040)$ & 0.52 \\
10W/138 & $3.4 \times 10^{3}\left(8.1 \times 10^{2}\right)$ & $5.77(7.78)$ & $0.057(0.001)$ & 0.91 \\
\hline
\end{tabular}

${ }^{a}$ Model: $Y=\left[Q^{\prime} /(4 \pi \alpha t)\right] \cdot \exp \left[-\left(s^{2} /(4 \alpha t)\right)\right] \cdot \exp (-\gamma t)$. Parameter descriptions are explained in the text.

${ }^{b}$ Nozzle/pressure $(\mathrm{kPa})$.

${ }^{\mathrm{c}} \mathrm{S}=$ Horizontal screen placed immediately below the spray nozzle. means showed the general trend of increasing $y$ with time and decreasing $y$ with distance for all treatments.

The main effect of treatment was not significant $(P>0.06)$, even though mean $y$ for the small nozzle $(10 \mathrm{~W} / 138 \mathrm{kPa})$ was low at all times and distances (Table 3). The other three treatments had similar mean $y$. Fruit disease incidence for $10 \mathrm{~W} / 138 \mathrm{kPa}$ was about a third of that of the standard treatment at $30 \mathrm{~cm}$ and less than a half at $60 \mathrm{~cm}$ from inoculum source. All interactions of treatment with other factors were not significant $(P>0.40)$.

\section{DISCUSSION}

Drop size distribution of rain was found to be an important determinant of splash dispersal of $C$. acutatum spores. Even though experimental treatments with high water pressure at the nozzle orifice $(10 \mathrm{~W} / 138 \mathrm{kPa}$ and $20 \mathrm{~W} / 138 \mathrm{kPa})$ had somewhat higher incident rain $(R)$ and splashed rain $\left(R_{s}\right)$ intensity (milliliters per square centimeter per hour) than the standard, idealized, naturalrain treatment $(20 \mathrm{~W} / 69 \mathrm{kPa})$, the standard treatment had significantly greater spore dispersal, as measured by colonies in gravity samplers. The higher rain intensity for nozzles with high pressure was achieved by the production of more but, on average, smaller drops than for the treatment with a natural rain. That is, the drop volume distribution was shifted to the left (Fig. 1), giving smaller $D_{0}^{\prime}$ values. Moreover, the treatment with the screen had the largest $D_{0}{ }^{\prime}$, splashed the highest volume of water and percentage of the incident rain, and resulted in considerably more dispersed spores than the other treatments. Overall, dispersal was highly and positively correlated with estimated $D_{0}^{\prime}$ of the rains (Fig. 1) and not related to $R$ of these deliberately altered generated rains.

In natural rains of a single type, increasing rain intensity is linked with increasing number of raindrops per unit of area and time (23) and also a shift of the drop size distribution to larger diameters (31). $D_{0}{ }^{\prime}$ increases from about $1.2 \mathrm{~mm}$ with a $2 \mathrm{~mm} / \mathrm{h}$ of (idealized) natural rain to about $2.5 \mathrm{~mm}$ with a $60 \mathrm{~mm} / \mathrm{h}$ of rain (30), with a corresponding increase in frequency of drops of any given diameter with increasing rain intensity. Drop size distribution is affected somewhat by type of rain episode, in addition to rain intensity (23). For instance, thunderstorms generally have larger $D_{0}^{\prime}$ (or $D_{0}$ ) than do showers or oceanographic rains (30). Thus, two rains of different types, but similar intensities, may vary considerably in kinetic energy (1), and more than simple intensity may be needed to assess risk of dispersal events (29).

Splashed rain intensity $\left(R_{s}\right)$ can be considered an indication of assumed total kinetic energy of impacting water drops, because results from controlled studies with single-drop impactions $(36,37)$ show that volume of splashed water from a strawberry fruit is a positive function of the incident water-drop kinetic energy. Other workers, using single-sized drops, found an increase in

TABLE 3. Mean proportion of strawberry fruit infected by Colletotrichum acutatum (y) for rain durations of 4 and 16 min and distances from inoculum source of 30 and $60 \mathrm{~cm}$ for four treatments

\begin{tabular}{lcccccc}
\hline & \multicolumn{2}{c}{$30 \mathrm{~cm}$} & & \multicolumn{2}{c}{$60 \mathrm{~cm}$} & \\
\cline { 2 - 3 } Treatment $^{\mathrm{a}}$ & $4 \mathrm{~min}$ & $16 \mathrm{~min}$ & & $4 \mathrm{~min}$ & $16 \mathrm{~min}$ & \multirow{2}{*}{ Mean } \\
\hline $20 \mathrm{~W} / 69$ & 0.250 & 0.433 & & 0.067 & 0.133 & 0.221 \\
& $(0.058)^{\mathrm{b}}$ & $(0.033)$ & & $(0.017)$ & $(0.044)$ & $(0.045)$ \\
$20 \mathrm{~W} / 138$ & 0.233 & 0.583 & & 0.067 & 0.150 & 0.258 \\
& $(0.017)$ & $(0.130)$ & & $(0.017)$ & $(0.058)$ & $(0.067)$ \\
$20 \mathrm{~W} / 69 \mathrm{~S}^{\mathrm{c}}$ & 0.217 & 0.707 & & 0.083 & 0.183 & 0.298 \\
& $(0.093)$ & $(0.203)$ & & $(0.017)$ & $(0.094)$ & $(0.089)$ \\
$10 \mathrm{~W} / 138$ & 0.083 & 0.150 & & 0.033 & 0.050 & 0.079 \\
& $(0.044)$ & $(0.058)$ & & $(0.033)$ & $(0.029)$ & $(0.020)$ \\
Mean & 0.196 & 0.468 & & 0.063 & 0.129 & \\
& $(0.032)$ & $(0.081)$ & $(0.011)$ & $(0.030)$ & \\
\hline
\end{tabular}

a Nozzle/pressure $(\mathrm{kPa})$.

b Standard error in parentheses.

c $\mathrm{S}=$ Horizontal screen placed immediately below the spray nozzle. 
splash dispersal of spores as the size of drops and, hence, velocity and kinetic energy, increased $(7,9,11,12,32,38)$. In our study, $R_{s}$ increased with increasing $D_{0}{ }^{\prime}$, except for the $20 \mathrm{~W} / 69 \mathrm{kPa}$ treatment. Since $D_{0}{ }^{\prime}$ is just a single measure of the cumulative volume distribution of rain, it may not fully reflect the kinetic energy of the generated rains. For a single drop, kinetic energy at impact is proportional to the cube of drop diameter times the velocity squared, and terminal velocity is proportional to the two-thirds power of drop diameter (19). Thus, kinetic energy for a drop at terminal velocity is directly related to drop diameter raised to the 4.3 power $(=3+[2 \times 0.67])$, and the largest drops contribute most of the total kinetic energy in a rain episode $(1,13)$. Therefore, slight changes in frequencies of large drops can have a major effect on total kinetic energy per unit of area and time. However, kinetic energy may not be the best indicator of dispersal, because $\Sigma$ was more related to $D_{0}{ }^{\prime}$ than to $R_{s}$. This is consistent with single-drop studies (37).

As expected $(18,19,24,39)$, infection of rain-exposed healthy fruit located near the inoculum source $(30 \mathrm{~cm})$ was higher than those located at $60 \mathrm{~cm}$. Also, infection was higher for fruit exposed to $16 \mathrm{~min}$ of rain than those exposed to only $4 \mathrm{~min}$. However, rain distribution alteration did not significantly affect fruit disease incidence. This was hypothesized because of the previously found nonlinear relationship between $R$ and $y$ (19), in which $y$ increased with $R$ to a maximum and then declined, primarily due to wash-off of spores from the fruit. Although dispersed spores increased here with $D_{0}{ }^{\prime}$, as discussed above, it is likely that washoff also increased. Thus, expanding on Madden et al. (19), increasing rain intensity or shifting drop distribution to larger sizes at a single intensity may not lead to greater disease incidence, even though more spores may be dispersed.

Deposition of $C$. acutatum spores into gravity samplers declined sharply with distance from the source, as expected $(3,4,6,11,22,39)$. Although most colonies of $C$. acutatum were located within $30 \mathrm{~cm}$ of the source, there were sufficient spores at $60 \mathrm{~cm}$ to result in infected fruit for all treatments. The diffusiontype model of Yang et al. (35) adequately described the colony data for three of the four treatments, and the estimated initial spore release parameter $\left(Q^{\prime}\right)$ increased with $D_{0}{ }^{\prime}$, and was strongly related to $\Sigma$. Madden et al. (19) previously found that $Q^{\prime}$ increased with $R$ for idealized rains of a single type. The estimated parameter of gradient length $(\alpha)$ was erratic, as found by Madden et al. (19) and Yang et al. (35). Moreover, the spore loss parameter $(\gamma)$ was not related to treatments, although the less satisfactory fit of the model to the data for the screen treatment (Table 2) may have precluded comparisons of $\gamma$. The $\gamma$ values for three treatments were similar, possibly reflecting the narrow range in $R$ tested here, compared with that used in Madden et al. (19).

Dispersal of inoculum by rain splash has been shown to be an important mechanism for disease spread over short distances in crops $(11,17,22,26,27)$. Wind $(3,4,22)$, ground cover (surface topography) $(16,34,38)$, and plant density (2) all alter splash dispersal. Still unresolved are the interactions, if any, of rain properties (e.g., intensity) and the surface and plant canopy characteristics.

\section{ACKNOWLEDGMENTS}

Research support and salaries provided by state and federal funds (especially USDA-NRI competitive grant 95-37303-1788) appropriated to Ohio Agricultural Research and Development Center (OARDC), The Ohio State University. Journal article 33-97.

\section{LITERATURE CITED}

1. Assouline, S., and Mualem, Y. 1989. The similarity of regional rainfall: A dimensionless model of drop size distribution. Trans. Am. Soc. Agric. Eng. 32:1216-1222.

2. Boudreau, M. A., and Madden, L. V. 1995. Effect of strawberry density on dispersal of Colletotrichum acutatum by simulated rain. Phytopathol- ogy 85:934-941

3. Brennan, R. M., Fitt, B. D. L., Taylor, G. C., and Colhoun, J. 1985. Dispersal of Septoria nodorum pycnidiospores by simulated raindrops in still air. Phytopathol. Z. 112:281-290.

4. Brennan, R. M., Fitt, B. D. L., Taylor, G. C., and Colhoun, J. 1985. Dispersal of Septoria nodorum pycnidiospores by simulated rain and wind. Phytopathol. Z. 112:291-297.

5. Eastburn, D. M., and Gubler, W. D. 1990. Strawberry anthracnose: Detection and survival of Colletotrichum acutatum in soil. Plant Dis. 74:161-163.

6. Fatemi, F., and Fitt, B. D. L. 1983. Dispersal of Pseudocercosporella herpotrichoides and Pyrenopeziza brassicae spores in splash droplets. Plant Pathol. 32:401-404.

7. Fitt, B. D. L., Creighton, N. F., Lacey, M. E., and McCartney, H. A. 1986. Effects of rainfall intensity and duration on dispersal of Rhynchosporium secalis conidia from infected barley leaves. Trans. Br. Mycol. Soc. 86:611-618.

8. Fitt, B. D. L., and McCartney, H. A. 1986. Spore dispersal in splash droplets. Pages 87-104 in: Water, Fungi and Plants. P. G. Ayres and L. Boddy, eds. Cambridge University Press, Cambridge.

9. Fitt, B. D. L., McCartney, H. A., Creighton, N. F., Lacey, M. E., and Walklate, P. J. 1988. Dispersal of Rhynchosporium secalis conidia from infected barley leaves or straw by simulated rain. Ann. Appl. Biol. 112:49-59.

10. Fitt, B. D. L., McCartney, H. A., and Walklate, P. J. 1989. The role of rain in dispersal of pathogen inoculum. Annu. Rev. Phytopathol. 27:241270 .

11. Grove, G. G., Madden, L. V., and Ellis, M. A. 1985. Splash dispersal of Phytophthora cactorum from infected strawberry fruit. Phytopathology 75:611-615.

12. Huber, L., Fitt, B. D. L., and McCartney, H. A. 1996. The incorporation of pathogen spores into rain-splash droplets: A modelling approach. Plant Pathol. 45:506-517.

13. Kinnell, P. I. A. 1981. Rainfall intensity-kinetic energy relationships for soil loss prediction. Soil Sci. Soc. Am. J. 45:153-155.

14. Madden, L. V. 1992. Rainfall and the dispersal of fungal spores. Adv. Plant Pathol. 8:39-79.

15. Madden, L. V. 1993. Aggregation of Colletotrichum acutatum in response to simulated rain episodes. J. Phytopathol. 138:145-156.

16. Madden, L. V., and Ellis, M. A. 1990. Effects of ground cover on splash dispersal of Phytophthora cactorum from strawberry fruits. J. Phytopathol. 129:170-174.

17. Madden, L. V., Wilson, L. L., and Ellis, M. A. 1993. Field spread of anthracnose fruit rot of strawberry in relation to ground cover and ambient weather conditions. Plant Dis. 77:861-866.

18. Madden, L. V., Wilson, L. L., Yang, X., and Ellis, M. A. 1992. Splash dispersal of Colletotrichum acutatum and Phytophthora cactorum by short-duration simulated rains. Plant Pathol. 41:427-436.

19. Madden, L. V., Yang, X., and Wilson, L. L. 1996. Effects of rain intensity on splash dispersal of Colletotrichum acutatum. Phytopathology 86:864-874.

20. Marshall, J. S., and Palmer, W. M. 1948. The distribution of raindrops with size. J. Meteorol. 5:165-166.

21. Ntahimpera, N., Madden, L. V., and Wilson, L. L. 1996. Effect of modified drop size distribution on the splash dispersal of Colletotrichum acutatum from infected strawberry fruit. (Abstr.) Phytopathology 86:S4.

22. Pedersen, E. A., Morrall, R. A. A., McCartney, H. A., and Fitt, B. D. L. 1994. Dispersal of conidia of Ascochyta fabae f. sp. lentis from infected lentil plants by simulated wind and rain. Plant Pathol. 43:50-55.

23. Prupacher, H. R., and Klett, J. D. 1980. Microphysics of Clouds and Precipitation. D. Reidel Publishing Co., Dordrecht, Holland.

24. Reynolds, K. M., Bulger, M. A., Madden, L. V., and Ellis, M. A. 1987. New methods using simulated rain to study the splash dispersal of plant pathogens. Phytopathology 77:921-926.

25. Reynolds, K. M., Madden, L. V., and Ellis, M. A. 1988. Effect of weather variables on strawberry leather rot epidemics. Phytopathology 78:822-827.

26. Reynolds, K. M., Madden, L. V., Reichard, D. L., and Ellis, M. A. 1987. Methods for study of raindrop impact on plant surfaces with application to predicting inoculum dispersal by rain. Phytopathology 77:226-232.

27. Reynolds, K. M., Madden, L. V., Reichard, D. L., and Ellis, M. A. 1989. Splash dispersal of Phytophthora cactorum from infected strawberry fruit by simulated canopy drip. Phytopathology 79:425-432.

28. Smith, B. J., and Black, L. L. 1990. Morphological, cultural, and pathogenic variation among Colletotrichum species isolated from strawberry. Plant Dis. 74:69-76.

29. Smith, J. A., and De Veaux, R. D. 1994. A stochastic model relating rainfall intensity to raindrop processes. Water Resour. Res. 30:651-664.

30. Ulbrich, C. W. 1983. Natural variations in the analytical form of the 
raindrop distribution. J. Clim. Appl. Meteorol. 22:1764-1775.

31. Ulbrich, C. W. 1985. The effects of drop size distribution truncation on rainfall integral parameters and empirical relations. J. Clim. Appl. Meteorol. 24:580-590.

32. Walklate, P. J., McCartney, H. A., and Fitt, B. D. L. 1989. Vertical dispersal of plant pathogens by splashing. Part II. Experimental study of the relationship between raindrop size and the maximum splash height. Plant Pathol. 38:64-70.

33. Wilson, L. L., Madden, L. V., and Ellis, M. A. 1990. Influence of temperature and wetness duration on infection of immature and mature strawberry fruit by Colletotrichum acutatum. Phytopathology 80:111-116.

34. Yang, X., and Madden, L. V. 1993. Effect of ground cover, rain intensity, and strawberry plants on splash of simulated raindrops. Agric. For. Meteorol. 65:1-20.

35. Yang, X., Madden, L. V., and Brazee, R. D. 1991. Application of the diffusion equation for modelling splash dispersal of point source pathogens. New Phytol. 118:295-301.

36. Yang, X., Madden, L. V., Reichard, D. L., Fox, R. D., and Ellis, M. A. 1991. Motion analysis of drop impaction on a strawberry surface. Agric. For. Meteorol. 56:67-92.

37. Yang, X., Madden, L. V., Reichard, D. L., Wilson, L. L., and Ellis, M. A 1992. Splash dispersal of Colletotrichum acutatum and Phytophthora cactorum from strawberry fruit by single drop impactions. Phytopathology 82:332-340

38. Yang, X., Madden, L. V., Wilson, L. L., and Ellis, M. A. 1990. Effects of surface topography and rain intensity on splash dispersal of Colletotrichum acutatum. Phytopathology 80:1115-1120.

39. Yang, X., Wilson, L. L., Madden, L. V., and Ellis, M. A. 1990. Rain splash dispersal of Colletotrichum acutatum from infected strawberry fruit. Phytopathology 80:590-595. 